\title{
A Review on Application of Formaldehyde in Cement-Based Materials
}

\author{
SKM. Pothinathan ${ }^{1, a^{*}}$, M. Muthukannan ${ }^{2, b}$, Narayanan Selvapalam ${ }^{3, c}$, \\ S. Christopher Gnanaraj ${ }^{4, d}$ \\ ${ }^{1}$ Department of Civil Engineering, Kalasalingam Academy of Research and Education, \\ Krishnankoil-626126, Tamilnadu, India \\ 2Department of Civil Engineering, Kalasalingam Academy of Research and Education, \\ Krishnankoil-626126, Tamilnadu, India \\ ${ }^{3}$ Department of Chemistry, Kalasalingam Academy of Research and Education, \\ Krishnankoil-626126, Tamilnadu, India \\ ${ }^{4}$ Department of Civil Engineering, Kalasalingam Academy of Research and Education, \\ Krishnankoil-626126, Tamilnadu, India \\ ${ }^{a}$ s.k.m.pothinathan@klu.ac.in, bm.muthukannan@klu.ac.in, ${ }^{\mathrm{c} n}$.selvapalam@klu.ac.in, \\ ${ }^{\mathrm{d}}$ S.christophergnanaraj@klu.ac.in
}

Keywords: Formaldehyde, Construction Material, Construction Industry, Admixture, Cement

\begin{abstract}
Formaldehyde is environment contamination, which causes irritation in the eyes, nose, and throat with concentration above 1.0ppm. But still, it is used as a construction material as an admixture and furthermore to make paints, adhesives, pressed wood, and flooring materials, etc. This paper reviews the impact of formaldehyde in the cement on flow, strength, and durability properties. In this most of the researchers studied the water reducing nature of formaldehyde-based cementitious materials (FBCM) because of its repulsive property, that can ensure improved workability and provides good mechanical strength. Finally, the challenges in the application of formaldehyde in cement-based materials are discussed to conclude some future scope in the field of the construction industry to use formaldehyde in cement.
\end{abstract}

\section{Introduction}

Formaldehyde is a by-product of naturally occurring organic material by the reaction with methane, oxygen, and other hydrocarbons in the presence of sunlight. Formaldehyde is a colorless component, and it is also adopting in several different forms like monomeric formaldehyde, trioxane, paraformaldehyde, and methanediol. Butlerov (1859), a Russian chemist, first reported the formaldehyde in the name of methylene dioxide in 1859. Hofmann announced the amalgamation techniques for formaldehyde in the laboratory by oxidation of methanol. Still, the Hofmann methods are in practice for making formaldehyde. Formaldehyde is not only used in construction industries and also for many industrial applications like to produce fabrics in the textile industry and to make brake shoes in the automobile industry. It is also used in making paints, foams, cosmetics, glues, adhesives, plywood, fiberboards, and to kill bacteria and fungi.

On the other hand, formaldehyde is an environmental pollutant, causes pungent-smell, eye and throat irritation, skin rash, and severe allergic reactions. IARC, 2004 stated the hazard value of formaldehyde depends on the concentration between 0.1 to $0.5 \mathrm{mg} / \mathrm{m} 3 \mathrm{slight}$ aggravation; at level 0.5 to $1 \mathrm{mg} / \mathrm{m} 3$ will irritate eyes, nose, and throat above $1 \mathrm{mg} / \mathrm{m} 3$ produce outrageous distress. So, the World Health Organization has suggested the concentration of formaldehyde indoor should be 
below $0.1 \mathrm{mg} / \mathrm{m} 3$. Liang et al. (2013) presumed that the indoor formaldehyde concentration of decay is faster up-to 4 hours, and it is controlled by natural ventilation. Chi et al (2016) investigated indoor air contamination and stated that the formaldehyde concentration is sensitive to humidity and temperature, and it is easily predictable. Kim and Joong (2005) contemplated the effect of polyvinyl acetate (PVA) addition in melamine and concluded that the addition of PVA of $30 \%$ reduces the formaldehyde concentration. Bourdin et al. (2014) studied the formaldehyde emission from the building materials in the newly build classroom (134.1m3) with one whiteboard, two interactive boards, five chairs, eleven doors, a varnished desk, and painted walls. He concludes that the indoor air quality was not exceeding $8.6 \mu \mathrm{g} / \mathrm{m} 3$, which is acceptable as per IARC,2004. Böhm et al. (2012) monitored the emission of formaldehyde from solid wood, blockboard, plywood, flooring, and furnishing materials. The higher concentration of investigated materials ranges from $0.006 \mathrm{mg} / \mathrm{m} 3$ to $0.048 \mathrm{mg} / \mathrm{m} 3$, which is very less while comparing the acceptable limits. Pierce et al. (2016) contemplated the assessment of indoor air formaldehyde concentration from laminate flooring in different duration for 63days, and the highest mean concentration range was $0.059 \mathrm{mg} / \mathrm{m} 3$, which is under threshold value. Therefore, the works of literature providing explicit knowledge about the concentration of formaldehyde is negligible. Due to any external factor, if the concentration is increased, it can be reduced by merely providing natural ventilation or by chemical action.

As a cement-based material, formaldehyde is widely used as admixtures in the construction industry to provide desired property to the concrete like increased workability, increased mechanical strength, reducing the water content, and making self-healing concrete. Many types of formaldehyde-based admixtures are available namely sulfonated melamine-formaldehyde, sulfonated naphthalene-formaldehyde, urea-formaldehyde resin, Aminosulfonatephenol-formaldehyde, Sulfanilate-phenol-formaldehyde, Sulfonated acetone-formaldehyde, Sodium sulfonilatephenol-formaldehyde, etc., The main purpose of the paper is to reviews research result on cement-based formaldehyde composites and discuss the rheological, mechanical and durability properties and conclude some future scope in the field of construction technology for the effective use of formaldehyde in cement.

\section{Types of formaldehyde in rheological application}

\section{Sulfonated melamine-formaldehyde (SMF)}

A study was conducted by Lahallh et al. (1988) about the SMF as a superplasticizer (SPs) in the concrete. He synthesized SMF in four different processes hydroxymethylation, sulfonation, low $\mathrm{pH}$ condensation, and high $\mathrm{pH}$ rearrangement with five different doses ranging from 1 percentage to 5 percentage. He found that the increase in superplasticizer leads to a decrease in yield stress and viscosity. He noted the slump of concrete was dropped after 1.75 hours to the original slump. He concluded that the $3 \%$ addition of admixture giving better flow properties if used within $45 \mathrm{~min}$ while comparing with commercial concrete. At the same time, no improvement was noted in the rheological property while increasing the dosage percentage. Collepardi (1998) compared the property of acrylic polymers (AP), SMF, and SNF as water-reducing agents in concrete. AP achieved flowing concrete with a low water-cement ratio than SMF and SNF. SMF and SNF also showed good result in slump loss but in the longer duration the advantage of using water reducers are negotiable, that means no effect in flow property.

Yilmaz et al. (1995) analyzed the influence of SMF in the hydration of cement. The retardation and acceleration of the cement are noted in different temperatures. SMF retards the setting time in low temperature (180C) and accelerates at high temperature ( $>400 \mathrm{C})$. Rols S et al. (1999) presented the influence of SMF and viscosity modifiers (VM) in self-compacting concrete. He 
discussed that the flow property of SMF admixed concrete was achieved but the self-compacting was not achieved without VM. VM helps to reduce the segregation and bleeding of concrete. Arosio et al. (2007) investigated the influence of SMF in building blocks using cement and clay paste. The patent also there in the manufacturing of SMF in 1994 by the inventor Spiratos (1994) and another patent to use the SMF as an additive by Absi-Halabi (1987).

Hekal and Kishar (1999) studied the SNF effect of ettringite formation. The percentage of SNF in the cement affects the size of the ettringite which results in the delayed setting during the early stage up to 24 hours. Mezhov et al. (2020) used three different commercial Polynaphtalene Sulfonate (PNS) with varying molecular weight as SP for his study. The SPs were dissolved in water and added to the cement paste. From the result, he concludes that the dosage and molecular weight of PNS plays important role in rheological property. Higher molecular weight PNS need a higher dosage to trigger the polymerization and the low molecular weight PNS highly retard the hydration process. Typical rheological behavior was observed at the dosage level of 0.2 percentage.

\section{Aminosulfonate phenol-formaldehyde (APF)}

The rheological property of super-plasticized cementitious material using aminosulfonatephenol-formaldehyde was studied by Pei et al. (2008) In this study, two APF named p-aminobenzenesulfonate (AS) and N-dimethylaminobenzenesulfonate (SDMAS) were used. The flow property of the AS and SDMAS are equal during the initial stage and comparatively high with the control specimen. But the SDMAS performed well than AS. $\mathrm{NH}_{2}$ group in the AS produced better hydrogen bonding and result in low flow property comparing to SDMAS. Zhao et al. (2012) synthesized sulfonated aminophenol using formaldehyde, phenol, acid, and sodium sulfanilate. The surface tension of the cement particles decreases with APF water reducers concentration increases. Zhao et al. (2015) used aminosulfonate -phenol-formaldehyde (APF) and aminosulfonate-bisphenol A- formaldehyde (ABPF) as SPs in his study. 0.3 percentage of incorporation of APF and $\mathrm{ABPF}$ in concrete result in 20 percent of water reduction. Further increasing the dosage of APF and ABPF, APF shows better water reduction than the ABPF. ABPF exhibits improved performance in slump loss because of high molecular ratio than APF.

\section{Sulfanilate-phenol-formaldehyde (SPF)}

Pei et al. (2000) used ulfanilate-phenol-formaldehyde as a superplasticizer in concrete and compared it with SNF and SMF conventional superplasticizers. SPF reduced water up to 18\% without affecting the workability. Due to strong absorption in cement paste SPF provides high rheological property comparing others. El-Didamony et al. (2012) contemplated the effect of sodium sulfanilate phenol formaldehyde in sulfate resisting cement. The result shows that the addition of SPF decreased water consistency. Slump increases with an increase in SPF due to the negative charge of sulfanilate groups in the SPF repulse and achieved good fluidity.

\section{Sulfonated acetone-formaldehyde (SAF)}

Pei et al. [2004] studied the effect of SAF as a superplasticizer in concrete. He concludes that the SAF having excellent property to control the slump loss and it is most suitable for using the pumping concrete. Mahmoud et al. (2010) studied the effect of using SAF as water reducers in concrete. The SAF in concrete reduces the water-cement ratio up to $19 \%$, air content decreased $1.9 \%$, and retardation increases in the increase in SPs content. Lou et al. (2012) used SAF as a superplasticizer with different molecular weights (MW) to study the absorption and dispersion properties. Results show the increase in MW decrease in water-cement ratio for the same workability. Due to the electrostatic repulsion of higher MW dispersibility of the cement paste 
increases. In the Zhang et al. (2015) study, SAF and black liquor were used to prepare copolymer and used as high range water reducers in concrete. He concludes that the pure SAF admixed cement paste increase fluidity and the presence of black liquor promotes the flow property up to $20 \%$ weight percentage. The temperature during the copolymerization also affects the fluidity property. The fluidity of the copolymer gave a better result than the pure SAF of temperature up to $100^{\circ} \mathrm{C}$. But the high temperature of copolymer leads to crosslinking to the molecules and reducing the fluidity.

Zhao et al. (2020) investigated water soluble SAF as a superplasticizer with two different synthesis methods. The first method was produced by the chemical reaction between sodium pyrosulfite, acetone, and formaldehyde. The second method was prepared from anhydrous sodium sulfite, acetone, and formaldehyde. In the first method, the SAF contains a higher molecular weight comparing to the second method. The first method SAF and second method SAF introduced to the concrete mix about 0.32 percentage and 0.48 percentage and the water content was reduced up to 19 percentage and 18 present age. SAF also increased the fluidity, air content, and setting time of concrete. Yang $\mathrm{Xu}$ et al. (2020) conducted a comparison study between amphoteric polycarboxylate (APC) and SAF in elevated temperatures above $60^{\circ} \mathrm{C}$. The author concludes that the APC performed well in rheological property that the SAF due to the repulsion effect. SAF has a longer absorption amount of cement practical than the APC which promotes the hydration process.

\section{Types of formaldehyde in strengthening application.}

\section{Sulfonated melamine-formaldehyde (SMF)}

In the Lahallh et al. (1988) experiment shows the 3\% addition of SMF shows improved compressive strength by 50 percentage, tensile strength enhanced by 26 percentage, flexural strength increased by eight percentage, and elastic modulus enhanced by $12 \%$. Based on the test result he concluded that the formaldehyde ratio does not affect the strength. Yunchao et al. (1995) compared High-sulfonated melamine-formaldehyde (HSMF) and SMF as water reducing agent in his study. HSMF is more effective superplasticizer (SPs) than SMF and no increase in the compressive strength was noticed in both HSMF and SMF.

Ramachandran V et al. (1995) studied the hydration of cement using SMF as SPs in different cement Type I to V as per ASTM. Compression strength result shows that the higher strength achieved in early stage of concreting and the difference gradually decreased after 3 days test. Type I cement performed well in addition to SMF, but Type V shows lower hydration and less strength development with SMF. For better results in Type V cement, it was suggested to keep the SMF level below 0.3 percentage. In Rols et al. (1999) study the self-leveling nature of concrete using SMF as SPs with the viscosity modifier starch and precipitated silica. A compression test was conducted in 1, 7,28, and 90days. The SMF admixed concrete gave elevated strength during the initial stage and achieved equal strength after 28days testing. This strength rise is because of the reaction with tricalcium silica at an initial age.

\section{Sulfonated naphthalene-formaldehyde (SNF)}

Theobald and Johann Plank (2020) used $\beta$-Naphthalene sulfonate formaldehyde as a seeding material with normal and finer Portland cement. He noticed an increase in the compressive strength in early-stage from 6 hours to 24 hours and at 28 days no significant change in strength for finer cement. This is because of the high reactive property of the finer cement. At the same time, the normal courser Portland cement has a less reactive nature and shows strength development after 10 hours. 


\section{Urea-formaldehyde resin (UF)}

Yue et al. (2000) observed the effect of UF treated cotton fiber in cement-based composite material. The UF treated plant fiber adhere with cement particle and produced dense concrete which results in high strength and water resistance. According to result of Faramarzi et al. (2016), UF as grouting material increased the compressive strength by 125 percent of the concrete specimen. UF grout filling the pores and voids of the specimen. Increasing the UF content results in increasing the strength of the injected specimen. Han et al. (2020) investigated the strength property of epoxy/urea-formaldehyde microcapsules into the cement mortar. Urea-formaldehyde is used as a shell and epoxy as a core for the microcapsule. 0 to 15 percentage microcapsules are added related to cement content. The compression strength result shows that increasing the microcapsule content decreasing the strength and fluidity property. This means the microcapsules affects the internal structure of the specimen.

\section{Aminosulfonate-phenol-formaldehyde (APF)}

Pei (2008) used AS and SDMAS based aminosulfonate-phenol-formaldehyde as a superplasticizer. The AS specimen having low w/c ratio than the SDMAS, which possesses higher strength property of AS at the 7days test. But in the 28 days test on compressive and bending strength, SDMAS are $1.54 \mathrm{~N} / \mathrm{mm}^{2}$ and $0.64 \mathrm{~N} / \mathrm{mm}^{2}$ higher than AS due to the inhibiting the hydration process. Zhao et al. (2015) compared the impact of APF and ABPF as water reducers in concrete. Both SPs enhanced the air content of the specimen. Increasing the SPs result in higher air content. Therefore, it should be limited for better strength. Due to less water-cement ratio, both SPs result in high compression and flexural strength. But APF performed a little higher in mechanical strength than the ABPF.

\section{Sulfanilate-phenol-formaldehyde (SPF)}

In the Pei et al. (2000) study the SPF performed well in rheology and strength property comparing with sulfonated naphthalene formaldehyde and sulfonated melamine formaldehyde. 7 days and 28days test was conducted for the compressive strength test. In both times SPF gave higher results than the others due to higher water reduction. El-Didamony et al. (2012) investigate the strength property of cement paste with SPF in sulphate resisting cement with silica fume. The addition of the SPF was delayed by 0 to $15 \mathrm{~min}$ in $5 \mathrm{~min}$ interval and the reaction of the delayed time was also noted. The compressive strength test was conducted in 1,3,7.28 and 90 days hydration. Due to the water reducing effect with delayed addition, the compression strength increases up to 10min delayed time. Because of the retarder effect of the polymer after 10min the strength property decreased. Pang et al. (2012) synthesized modified SPF and studied the water reducing effect in concrete. Modified SPF has incredible repulsion force to cement particles, particularly with a low water-cement ratio. 0.6 percentage addition of modified SPF resulting in $18 \%$ water reduction and reduce the bleeding of mortar. This water reduction leads to higher mechanical strength.

\section{Sulfonated acetone-formaldehyde (SAF)}

Pei et al. (2004) used SAF to enhance the strength property of the concrete. And noted that the plasticizing effect of SAF admixed concrete improved the compressive strength in 3, 7, 28 days test. Zhang et al. (2015) investigated the strength behavior of superplasticizer admixed cement paste using the copolymers SAF and black liquor. He conducted 1,3,7 and 28 days of compression strength tests with varying dosages of copolymers. Due to the retarding effect the 1-day strength property of admixed paste is inferior to the control specimen. The result shows the gradual increase in compression strength by means of the age of the paste from 3days onwards. The usage 
of copolymer reduces the pore volume up to $6 \%$ which results in increasing the strength and promoting the long-term strength.

Zhao et al. (2020) studied two different synthesis method shows improved strength characteristics than the normal concrete because of less water percentage. Comparatively, the first method shows higher mechanical properties for the reason of higher water reducing rate. This improved strength result was achieved in all mechanical properties test like compression, tension, and ultra-sonic pulse velocity test. The curing period has a positive impact on the mechanical strength with means at 28 days test the result shows a rapid increase in strength in all test. In the Xu et al. (2020) study the APC and SAF as used as superplasticizers and compared the effects in mechanical property. The test was conducted on 1, 3, and 7days and the test results show no noticeable strength rise up to 3 days in both control and admixed specimen. But with the APC admixed specimens have low porosity and show improved microstructure which leads to higher mechanical strength than the SAF after 3 days. Mahmoud et al. (2010) performed the strength test using SAF in concrete. Using 2 percentage SAF the specimen yields higher compressive strength. This strength rise is directly related to water reduction and air content in the concrete.

\section{Performance of formaldehyde in durability condition}

\section{Sulfonated melamine-formaldehyde (SMF)}

The effect of SMF on the creep of concrete is studied by Lahallh et al. (1988) for a year as per ASTM C512. He observed that the deformation of concrete was controlled by 30 percentage while treated by three percentage of superplasticizer in concrete, and the creep modulus of treated concrete was almost twice the value of untreated concrete with a superplasticizer.

\section{Sulfonated acetone-formaldehyde (SAF)}

To perform a durability study Mahmoud et al. (2010) used sulphate and acid attack test. SAF admixed concrete specimens are immersed for about 6 months in the sulfuric acid for acid attack test and magnesium sulphate for sulphate resisting test. The use of SAF decreases water absorption and pores. That results increased durability property in an antagonistic environment.

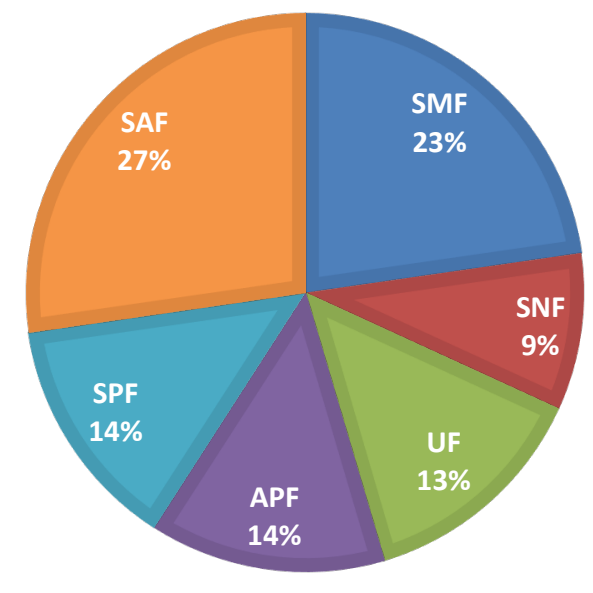

Fig. 1. Different types of formaldehyde-based admixtures used in this paper 


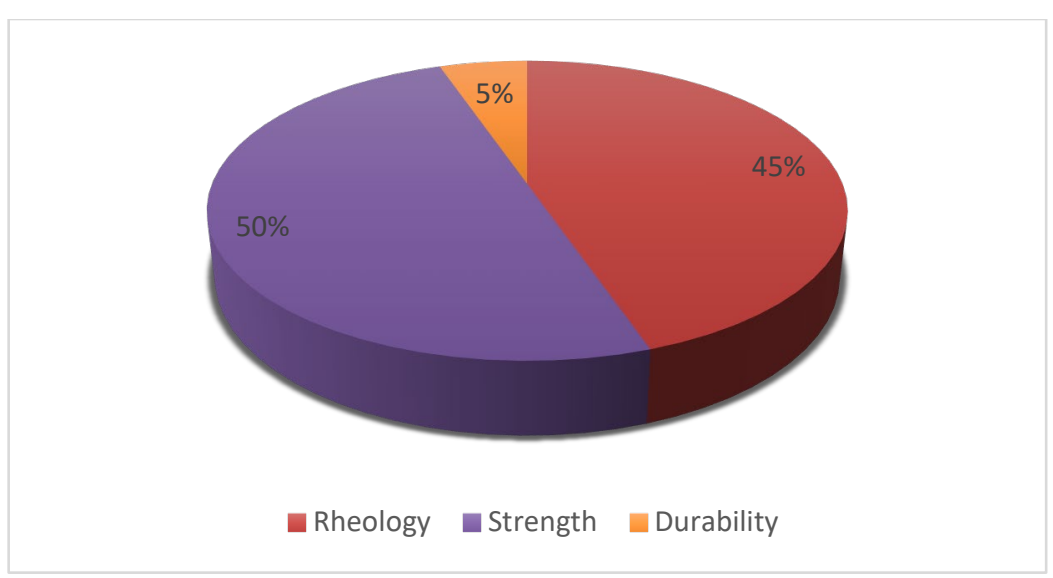

Fig.2. Properties reviewed in this paper

\section{Research Summary}

Cement is a widely used building material, which is not suitable for all the environmental conditions. To implicate special property to the normal cement/mortar/concrete, admixtures are used. In this paper formaldehyde-based cementitious (FBCM) construction materials and their effects were studied. There are approximately 37 papers were studied. The majority of the researchers focused on using formaldehyde as high range water reducers and some used it in self-healing and self-compacting/leveling. In this paper rheological, mechanical properties, and durability properties were noted and the effect of different types of SPs was also summarized. Fig.1. shows the percentage of different types of formaldehyde-based cementitious used among 37 reviewed papers. $23 \%$ of sulfonated melamine-formaldehyde (SMF), $9 \%$ of sulfonated naphthalene-formaldehyde (SNF), '13\% of urea-formaldehyde resin (UF), $14 \%$ of Aminosulfonate-phenol-formaldehyde (APF), 14\% of Sulfanilate-phenol-formaldehyde (SPF), and $27 \%$ of Sulfonated acetone-formaldehyde (SAF). It seems that more work is done using SAF and SMF. Fig.2. shows the properties reviewed using the above said formaldehyde-based cementitious materials. 45 percentage rheology property, 50 percentage strength property, and only 5 percentage of durability properties have been studies. In this most of the researchers studied the water reducing nature of FBCM because of its repulsive property and some FBCM particularly urea-formaldehyde resin used to make self-healing concrete and UF are mixed with concrete as microcapsule form. From this research overview, it clearly shows that formaldehyde is an inevitable construction material. It improves the cementitious property and shows great advantages in practical application. The pollution and hazard of the formaldehyde can be minimized by following the standard guidelines like IARC, 2004 hazard value.

\section{Conclusion}

This session discussed the future scope and research ideas in the field of using formaldehyde-based cementitious material ( $\mathrm{FBCM}$ ). Comparing the commercially available cement FBCM provides excellent fresh and hardened properties particularly using FBCM as superplasticizer it gives outstanding rheological with minimum water-cement ratio and its leads to higher mechanical strength. It found that most of the researchers concentrated on rheological and strength properties. But FBCM also uses for bonding old and new concrete, grouting, self-healing, making insulating foam boards, tiles, and manufacturing brick, etc., It also observed that less work was conducted on durability and temperature effects and need to be studied in a detailed manner. Formaldehyde based polymer materials also there to enhance the property of concrete. 


\section{References}

[1] Arosio F, Castoldi L, Ferlazzo N, \& Forzatti P (2007) Influence of solfonated melamine formaldehyde condensate on the quality of building blocks production by extrusion of cementclay pastes. Applied Clay Science, 35(1-2):85-93. https://doi.org/10.1016/j.clay.2006.06.004

[2] Böhm M, Salem MZM, Srba J (2012) Formaldehyde emission monitoring from a variety of solid wood, plywood, blockboard and flooring products manufactured for building and furnishing materials. Journal of Hazardous Materials 221:68- 79. https://doi.org/10.1016/j.conbuildmat.2020.120240

[3] Bourdin D, Mocho P, Desauziers V, Plaisance H (2014) Formaldehyde emission behavior of building materials: On-site measurements and modeling approach to predict indoor air pollution. Journal of Hazardous Materials 280:164-173. https://doi.org/10.1016/j.jhazmat.2014.07.065

[4] Butlerow A (1859) Ueber einige Derivate des Jodmethylens [On some derivatives of methylene iodide]. Annalen der Chemie und Pharmacie. 111:242-252.

https://doi.org/10.1002/jlac.18591110219

[5] Chi C, Chen W, Guo M, Weng M, Yan G, Shen X. (2016). Law and features of TVOC and Formaldehyde pollution in urban indoor air. Atmospheric Environment. 132:85-90. https://doi.org/10.1016/j.atmosenv.2016.02.043

[6] Collepardi M (1998) Admixtures used to enhance placing characteristics of concrete. Cement and Concrete Composites 20(2-3):103-112. https://doi.org/10.1016/S0958-9465(98)00071-7

[7] Didamony E, Heikal M, Aleem SAE (2012) Influence of delayed addition time of sodium sulfanilate phenol formaldehyde condensate on the hydration characteristics of sulfate resisting cement pastes containing silica fume. Construction and Building Materials 37:269-276. https://doi.org/10.1016/j.conbuildmat.2012.07.023

[8] Faramarzi L, Rasti A, Abtahi SM (2016) An experimental study of the effect of cement and chemical grouting on the improvement of the mechanical and hydraulic properties of alluvial formations. Construction and Building Materials 126:32-43. https://doi.org/10.1016/j.conbuildmat.2016.09.006

[9] Han T, Wang X, Li D, Li D, F Xing, N Han (2020) Influence of strain rate on mechanical characteristic and pore structure of self-healing cementitious composites with epoxy/urea-formaldehyde microcapsules. Construction and Building Materials. https://doi.org/10.1016/j.conbuildmat.2020.121138

[10] Hekal EE, \& Kishar EA (1999) Effect of sodium salt of naphthalene-formaldehyde polycondensate on ettringite formation. Cement and Concrete Research 29(10):1535-1540, DOI: https://doi.org/10.1016/S0008-8846(99)00110-6

[11] Kim S, Kim HJ (2005) Effect of addition of polyvinyl acetate to melamine-formaldehyde resin on the adhesion and formaldehyde emission in engineered flooring, International Journal of Adhesion \& Adhesives 25:456-461. https://doi.org/10.1016/j.ijadhadh.2005.01.001

[12] Lahallh SM, Halabi MA, Mali A (1988) Effect of polymerization conditions of sulfonated-melamine formaldehyde superplasticizers on concrete. Cement and Concrete Research 18:513-531. https://doi.org/10.1016/0008-8846(88)90044-0

[13] Lahalih S, Absi-Halabi M (1987) Highly stable sulfonated melamine-formaldehyde condensate solution. Patent no: US4820766A, 
[14] Li W, Zhu X, Zhao N, Jiang Z (2016) Preparation and Properties of Melamine Urea-Formaldehyde Microcapsules for Self-Healing of Cementitious Materials. Materials, 9(3). https://doi.org/10.3390/ma9030152

[15] Liang W, Yang X (2013) Indoor formaldehyde in real buildings: Emission source identification, overall emission rate estimation, concentration increase and decay patterns, Building and Environment 69 :114-120. https://doi.org/10.1016/j.buildenv.2013.08.009

[16] Lou H, Ji K, Lin H, Pang Y, Deng Y, Qiu X, Zhang H, Xie Z (2012) Effect of molecular weight of sulphonated acetone-formaldehyde condensate on its adsorption and dispersion properties in cementitious system. Cement and Concrete Research 42:1043-1048. https://doi.org/10.1016/j.cemconres.2011.11.002

[17] Mahmoud AAM, Shehab MSH, El-Dieb AS (2010) Concrete mixtures incorporating synthesized sulfonated acetophenone-formaldehyde resin as superplasticizer. Cement and Concrete Composites, 32(5):392-397. https://doi.org/10.1016/j.cemconcomp.2010.02.005

[18] Mezhov A, Ulka A, Gendel Y, Charles E. Diesendruck, Konstantin Kovler (2020) The working mechanisms of low molecular weight polynaphthalene sulfonate superplasticizers. Construction and Building Materials, 240. https://doi.org/10.1016/j.conbuildmat.2019.117891

[19] Pang Y, Wen WN, Lou HM, Ouyang XP, Qiu XQ (2012) Synthesis of Lignin-Modified Sulfanilate-Phenol-Formaldehyde Condensate and Application as Concrete Superplasticizer. Applied Mechanics and Materials, 174-177:1238-1246. https://doi.org/10.4028/www.scientific.net/AMM.174-177.1238

[20] Pei M, Wang D, Hu X, Xu D (2000) Synthesis of sodium sulfanilate-phenol-formaldehyde condensate and its application as a superplasticizer in concrete. Cement and Concrete Research 30:1841-1845. https://doi.org/10.1016/S0008-8846(00)00389-6

[21] Pei M, Yang Y, Zhang X, Zhang J, Dong J (2004) Synthesis and the effects of water-soluble sulfonated acetone-formaldehyde resin on the properties of concrete. Cement and Concrete Research. 34:1417-1420. https://doi.org/10.1016/j.cemconres.2004.01.012

[22] Pei M, Wang Z, Li W, Zhang J, Pan Q, Qin X (2008) The properties of cementitious materials superplasticized with two superplasticizers based on aminosulfonate-phenolformaldehyde. Construction and Building Materials 22:2382-2385.

https://doi.org/10.1016/j.conbuildmat.2007.09.003

[23] Pierce JS, Abelmann A, Lotter JT, Ruestow PS, Unice KM, Beckett EM, Fritz HA, Bare JL, Finley BL (2016) An assessment of formaldehyde emissions from laminate flooring manufactured in China. Regulatory Toxicology and Pharmacology 81:20-32.

https://doi.org/10.1016/j.yrtph.2016.06.022

[24] Ramachandran V S, Lowery MS, \& Malhotra VM (1995) Behaviour of ASTM Type V cement hydrated in the presence of sulfonated melamine formaldehyde. Materials and Structures, 28(3):133-138. https://doi.org/10.1007/BF02473220

[25] Rols S, Ambroise J, \& Péra J (1999) Effects of different viscosity agents on the properties of self-leveling concrete. Cement and Concrete Research, 29(2):261-266.

https://doi.org/10.1016/S0008-8846(98)00095-7

[26] Spiratos MD (1994) Processes for manufacture of sulfonated melamine-formaldehyde resins. Patent no: US5424390A,

[27] Theobald M, Plank J (2020) $\beta$-Naphthalene sulfonate formaldehyde-based nanocomposites 
as new seeding materials for Portland cement. Construction and Building Materials 264. https://doi.org/10.1016/j.conbuildmat.2020.120240

[28] Xu Y, Hua M, Chen D, Liu Z, Yu Y, H Zhang, J Guo (2020) Performance and working mechanism of amphoteric polycarboxylate-based dispersant and sulfonated acetone formaldehyde polycondensate-based dispersant in oil well cement. Construction and Building Materials 233. https://doi.org/10.1016/j.conbuildmat.2019.117147

[29] Yilmaz VT, \& Glasser FP (1989) Influence of sulphonated melamine formaldehyde superplasticizer on cement hydration and microstructure. Advances in Cement Research, V:2(7), P:111-119. https://doi.org/10.1680/adcr.1989.2.7.111

[30] Yilmaz VT, Kindness A, \& Glasser FP (1989) Quantitative analysis of sulphonated melamine formaldehyde superplasticizer in cement. Advances in Cement Research, 2(7):107-110. https://doi.org/10.1680/adcr.1989.2.7.107

[31] Yue Y, Li G, Xu X, Zhao Z. (2000). Properties and microstructures of plant-fiber-reinforced cement-based composites. Cement and Concrete Research, 30(12):1983-1986. https://doi.org/10.1016/S0008-8846(00)00376-8

[32] Yunchao H, Fansen Z, Hu Y, Chunying L, Zhaoqiang W, Weining L, \& Shukai Y (1995) Synthesis and properties of high-sulfonated melamine-formaldehyde resin. Journal of Applied Polymer Science, 56(12):1523-1526. https://doi.org/10.1002/app.1995.070561201

[33] Zhang T, Gao J, Deng X, Liu Y (2015) Graft copolymerization of black liquor and sulfonated acetone formaldehyde and research on concrete performance. Construction and Building Materials 83:308-313. https://doi.org/10.1016/j.conbuildmat.2015.03.046

[34] Zhao H, Zhou W, \& Gao B (2012) Synthesis and dispersion mechanism of AH polymers on cement particles. Advances in Cement Research, 24(1):41-47.

https://doi.org/10.1680/adcr.2012.24.1.41

[35] Zhao H, H Zhao, \& Deng M (2015) Feasibility Study on Bisphenol A as Phenol Replacement to Produce Aminosulfonate-Phenol-Formaldehyde Superplasticizer for Application in Concrete. Journal of Materials in Civil Engineering, 27(6). https://doi.org/10.1061/(ASCE)MT.1943-5533.0001141

[36] Zhao H, Deng M, Tang M (2020) The molecular structures and the application properties of sulfonated acetone-formaldehyde superplasticizers at different synthetic methods. Construction and Building Materials 241. https://doi.org/10.1016/j.conbuildmat.2020.118051

[37] Zhu H, Xu S (2019) Synthesis and properties of rigid polyurethane foams synthesized from modified urea-formaldehyde resin. Construction and Building Materials. 202:718-726.

https://doi.org/10.1016/j.conbuildmat.2019.01.035 